\title{
A SOCIAL WELFARE VIEW OF THE MEASUREMENT OF INCOME EQUALITY
}

\author{
By D. J. Aigner And A. J. Heins \\ University of Illinois
}

Economists' use of the term "equality" in reference to a distribution of incomes has historically been in the sense of a consensus for some statistical characteristic(s) of the distribution rather than a firm concept of equality. Of course such a concept rests on appropriate welfare assumptions about income and its distribution, assumptions which, for the most part, have been left implicit (and unknown) in discussions of income equality in the literature.

Our purpose in this paper is dual: first, we wish to discover an unambiguous, welfare-related equality measure. This we accomplish through suitable assumptions on a social welfare function. What is produced is an "index" of equality which describes the performance of a given distribution relative to the maximum welfare derivable from the total income it represents. The measure thus depends functionally on the welfare attributes of income, something which in reality we know little about.

This impasse leads us to inquire into the sensitivity of the index over specifications of the welfare function, which is done by comparing equality ranks for the states of the United States for 1960 under various functional forms and among curves within a given form. As an interesting secondary issue, the performance of traditional equality measures is tested relative to the welfareoriented index to discover implications about their welfare content.

It is found that the equality index is, in certain ranges for the welfare function, insensitive to its specification. The findings lead directly to conclusions concerning traditional equality measures, their usefulness in correctly accounting for equality differences among alternative income distributions and, concomitantly, their implicit welfare inputs.

When economists make judgments about equality in a distribution of income or between income distribution alternatives, those judgments are usually couched in terms of the ceteris paribus preference for a more equal distribution. Adherence to this rule of selection must necessarily imply the use of additional assumptions concerning the social welfare attached to income and its distribution, either through a social welfare function specified by the observer or by a simple consensus of thought as to the preference of greater income equality.

Unfortunately our operational measures of equality, e.g., the Gini concentration ratio, coefficient of variation, etc., are only statistical devices. They measure the relative dispersion of a frequency distribution of income without reference to the normative judgments necessarily involved in describing that same distribution as "good" or "bad" in terms of the welfare it imputes to society. It is not that these measures in themselves should contain welfare attributes. The 
point is when welfare judgments are made based upon them, the observer must be making certain assumptions about the relation between income, its distribution, and the welfare of society. Depending on what these assumptions are, objective, statistical measures of income equality may or may not yield a correct indication of equality in the normative sense.

For example, in 1960 the state of Connecticut possessed a more equal distribution of income than did Oregon, as measured by Gini's concentration ratio. Using the coefficient of variation as the equality measure, however, Oregon's income distribution was the more equal. ${ }^{1}$ Given this inconsistency, and for whatever purpose such a comparison may be meaningful, which state had the preferred, more "equal" distribution of income? Quite clearly, since neither measure contains explicit normative inputs, the issue cannot be decided without reference to assumptions that relate income to welfare. A simple consensus that one measure is somehow "better" than the other is not at all a satisfactory substitute for such assumptions. As we shall see below, however, such a consensus may be viewed as implying certain welfare-income assumptions.

The methodology we shall employ in this paper in order to elaborate on the appropriateness, from a social welfare point-of-view, of various measures of income equality rests on the specification of a functional relationship between income and welfare. A theoretical equality measure is first derived via a general specification of the social welfare function and a maximization of welfare from a given income for society as a whole. The remainder of the paper is concerned with an empirical evaluation of the popular equality measures relative to this "ideal" measure.

While empirical necessity requires that we make some restrictive assumptions about the general income-welfare relationship, our results demonstrate that certain conclusions as to the appropriateness of the measures in question are rather insensitive to the specification of a social welfare function and may be therefore of greater generality than the assumptions imposed would dictate on an $e x$ ante basis.

\section{A Soctal Welfare Measure of Income Equality}

Let us begin by assuming there exists a functional relationship between income and welfare. Let

$$
W=W\left(x_{1}, \ldots, x_{n}\right)
$$

where $x_{i}$ is the income of the $i^{\text {th }}$ individual in society. Then $W$ may be regarded as the appropriate social welfare function, which we shall further assume to possess the following properties:

$$
\begin{aligned}
\partial W / \partial x_{i} & >0, \quad i=1, \ldots, n, \\
\partial W / \partial x_{i} & =\partial W / \partial x_{\jmath} \quad \text { for } x_{i}=x_{j}, \\
\partial^{2} W / \partial x_{i}^{2} & <0, \quad i=1, \ldots, n .
\end{aligned}
$$

It is also assumed that incomes are always non-negative.

1. Cf. Table 1, below. 
These assumptions in effect require that increments to social welfare by reason of increments to an individual's income are positive and that welfare increments decline as income increases. This particular form of the welfare function might be specified by an egalitarian observer who judges that society is better off, ceteris paribus, when resources (in the form of money incomes) are equalized among individuals. In this case the rate at which incremental welfare declines in the social welfare function expresses the intensity of desire for the egalitarian society. Alternatively the function as specified by the conditions (2), (3), and (4) might be viewed in the utilitarian sense that individuals have equal but declining capacities for the enjoyment of additional income. Presumably a desire to discuss the income distribution of society in a preferential sense reflects one or the other of these normative judgments.

Suppose that society in the aggregate receives money income $I$. It is a straightforward matter to show that the function $W$ obtains a maximum for this fixed total income $I$ when the following condition holds:

$$
\partial W / \partial x_{1}=\ldots=\partial W / \partial x_{n}=\lambda>0,
$$

where $\lambda$ is the Lagrangian multiplier. Assumption (4) is sufficient for $W$ to reach a maximum at that set of $x_{i}$ 's for which (5) holds. From equation (3) it follows directly that this optimum set of incomes occurs precisely when each individual in society receives an equal income, that is

$$
\operatorname{Max}_{\{x,\}} W(I)=W(\bar{x}, \ldots, \bar{x}, I),
$$

where $\bar{x}={ }_{i} x_{i} / n=I / n$. The maximum occurs when each individual receives the mean incomc. Thus any alternative distribution of incomes must, under the specifications adopted for $W$, produce social welfare at best equal to the distribution $(\bar{x}, \ldots, \bar{x})$. An index of equality for a given distribution may easily be defined in terms of its correspondence to the maximum possible welfare derivable from the total income $I$. Specifically, let the index be $E$, where

$$
E(W, I)=\frac{W\left(x_{1}, \ldots, x_{n}, I\right)}{W(\bar{x}, \ldots, \bar{x}, I)} \leqq 1 .^{2}
$$

Large values of $E$ denote greater equality in the distribution of the given income $I$.

Considering equality of the income distribution in this fashion offers several advantages over "objective" definitions. First, (7) makes it quite clear that a social welfare function $W\left(x_{1}, \ldots, x_{n}\right)$ must be specified before equality judgments ean be made in a preferential sense. Moreover, if society can specify the appropriate welfare function (or range of functions, as we will see later), then judgments can be made concerning policies affecting the distribution of income with confidence that those judgments reflect the specified function. Lastly, a comparison of equality judgments rendered by the traditional measures with

2. Hugh Dalton [4] proposed a remarkably similar measure of equality as early as 1920 , but failed to develop his notion in terms of general welfare functions. While he did recognize some of the implications of such a specification which we will discuss presently, he apparently did not believe that the then available statistics of income distribution were suitable for this method of measuring equality. 
analogous results obtained from an application of equation (7) under various assumptions about the form of $W$ enables some introspeetion as to welfare functions implicit in each of the traditional measures, and hence their appropriateness viewed through the implicit assumptions.

\section{Operational Specification of the Equality Index}

Any actual attempt to compute $E$ as defined by (7) must clearly include a specification of $W$ in explicit form. And, to be sure, any such specification is arbitrary within the context of the class of admissible functions. In practice information about the income distribution appears as a grouped frequency distribution; any limiting assumption to be made will thus concern the interactions of individual incomes in $W$.

For our purposes the specification adopted is one of independence of individual income-welfare contributions at the margin. That is, we assume some $\bar{W}$ is given, where

$$
\partial^{2} W / \partial x_{i} \partial x_{j}=0, \quad i \neq j, \quad i, j=1, \ldots, n .
$$

Such an assumption is tantamount to an independence hypothesis of the form:

$$
\vec{W}=\sum_{i=1}^{n} W\left(x_{i}\right)
$$

so that interactions in the welfare function between individual incomes are presumed non-existent. While such interactions may be present in real-world society, this assumption is certainly more acceptable than its analogue in utility terms, where phenomena like "keeping up with the Joneses" are disallowed. Of course, (8) is also sufficient for the existence of Pareto optimality for the incomewelfare relationship.

Translating the assumption into terms amcnable to an operational statement of $E$, if $f(x)$ is the frequency distribution of income $I$ in society and $W(x)$ is the welfare function defined by (2)-(4) and (8), then $E$ becomes:

$$
E=\frac{\int_{0}^{\infty} \bar{W}(x) f(x) d x}{\bar{W}(\bar{x}) \int_{0}^{\infty} f(x) d x} \leqq 1 .
$$

As will be seen from the numerical results, the assumptions (2) and (8) may not be as limiting on ex post grounds as they might appear ex ante. At least the empirical evidence would suggest some degree of insensitivity of the results to variations in $\bar{W}(x)$.

\section{EMPIRICAL RESUlts}

To implement comparisons of $E$ and more traditional indicators of income equality, three forms of $\bar{W}(x)$ were selected, each reflecting the assumptions (2) $-(4)$ and (8), as follows: 


$$
\begin{aligned}
& \bar{W}_{1}^{\prime}=\frac{d \bar{W}_{1}}{d x}=\mathrm{e}^{-x / 3} \\
& \bar{W}_{2}^{\prime}=\left(\frac{x}{\phi}+1\right)^{-1} \\
& \bar{W}_{3}^{\prime}=\left(\frac{x}{\theta}+1\right)^{-2}
\end{aligned}
$$

yielding

$$
\begin{aligned}
& \bar{W}_{1}=\beta\left(1-\mathrm{e}^{-x / \beta}\right) \\
& \bar{W}_{2}=\phi \log _{\mathrm{e}}\left(\frac{x}{\phi}+1\right) \\
& \bar{W}_{2}=\frac{\theta x}{\theta+x} .
\end{aligned}
$$

These forms are pictured in Figure 1 for selected parameter values. Through manipulation of $\beta, \phi$, and $\theta$ a myriad of shapes for the welfare function is possible within the general restrictions imposed above.

Based on these functions, the equality measure $E$ was computed for 1960 family income distributions in the fifty states and the District of Columbia using various parameter specifications. Computations were then carried out for the "concentration ratio,"3 coefficient of variation, Pareto's $\alpha$ and Gini's $\delta$, and the percentage of aggregate income earned by the top one, five, and ten per cent of the income earners. ${ }^{4}$

Table I shows the results for three selected $E(\bar{W})$ forms and for the traditional measures of equality exclusive of the top five per cent measure which is omitted here in the interest of space. In each case the states have been ranked from greatest to least equality.

On inspection there appears to be a close relationship between most of the measures of equality considered. As between alternative normative indexes, the order of equality is not very different. Similarly, this ordering approximates closely the order generated by the concentration ratio and coefficient of variation, but less closely the orderings derived from the Pareto $\alpha$, Gini $\delta$, and the per cent of aggregate income measures.

3. Not Gini's concentration ratio: Gini's ratio is the ratio of the area between the Lorenz curve and the 45-degree line to the total area enclosed by the 45 -degree line. Hence, the closer this ratio to zero, the greater is equality. Hereinafter we refer to one minus this ratio as the "concentration ratio."

4. Both the Gini and Pareto lines were fitted only to those classes above the median class. Hence, any implications with regard to inequality apply only within the predescribed range (cf. Bowman [3]). The excellence of fit obtained for the Pareto line applied to the high income tail of the distributions allows for a useful estimation procedure for determining class means in this range (cf. Appendix). Computing Pareto's a only for the upper tail yields values higher (absolutely) than would be obtained for the entire distribution; however, the original Pareto work was done using only the upper end of the income distribution since detailed data on the lower end of the distribution was not available in his time. Our results suggest that the Pareto notion of a fixed $\alpha(1.50)$ should be re-evaluated, and bear directly upon the work of Mandelbrot [10]. 


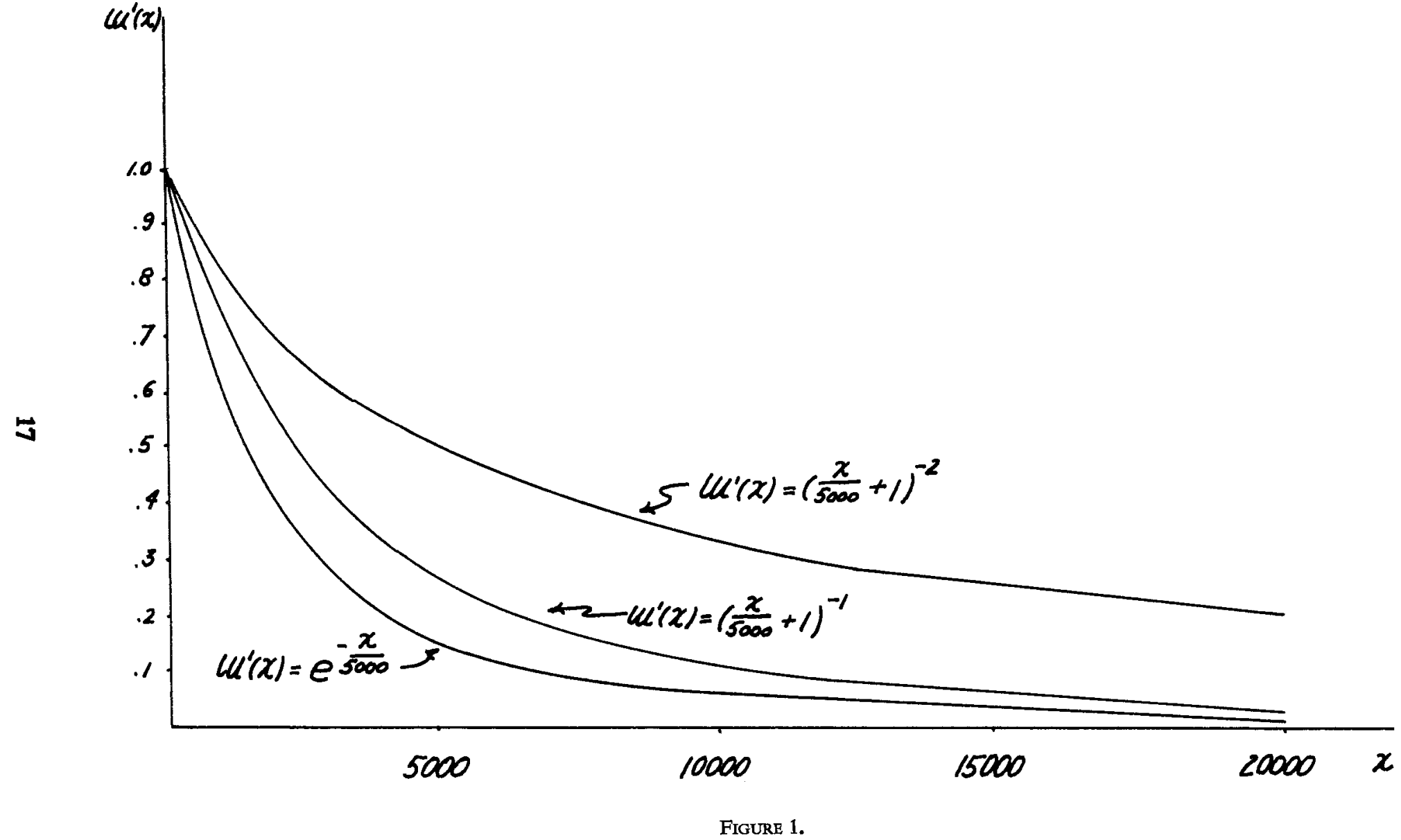


TABLE I

Various Measures of Equality of Income for the FifTy STates and the District of Columbia

(Rankings From Greatest to Least Equality Are Enclosed in Parentheses)

\begin{tabular}{|c|c|c|c|c|c|c|c|c|c|}
\hline \multirow{2}{*}{$\begin{array}{l}\text { Measures of } \\
\text { Equality }\end{array}$} & \multicolumn{3}{|c|}{$E$} & \multirow[b]{2}{*}{$\begin{array}{c}\text { Concentration } \\
\text { ratio } \%\end{array}$} & \multirow{2}{*}{$\begin{array}{c}\text { Coefficient } \\
\text { of } \\
\text { variation }\end{array}$} & \multirow[b]{2}{*}{$\begin{array}{l}\text { Pareto } \\
\text { coefficient }\end{array}$} & \multirow[b]{2}{*}{$\begin{array}{l}\text { Gini } \\
\text { coefficient }\end{array}$} & \multicolumn{2}{|c|}{$\begin{array}{l}\text { Per cent of total } \\
\text { income earned by }\end{array}$} \\
\hline & $\begin{array}{c}\bar{W}_{1} \\
\beta=5000\end{array}$ & $\begin{array}{c}\bar{W}_{2} \\
\phi=5000\end{array}$ & $\begin{array}{c}\bar{W}_{3} \\
\theta=5000\end{array}$ & & & & & Top $1 \%$ & Top $10 \%$ \\
\hline Alabama & $.840(46)$ & $.891(46)$ & $.853(48)$ & $56.8(48)$ & $95.9(44)$ & $2.48(40)$ & $1.62(34)$ & $7.3(38)$ & $30.1(42)$ \\
\hline Alaska & $.878(23)$ & $919(19)$ & $.899(21)$ & $65.0(19)$ & $69.0(1)$ & $3.11(1)$ & $1.43(1)$ & $4.9(1)$ & $24.7(1)$ \\
\hline Arizona & $.861(33)$ & $.904(35)$ & $.881(32)$ & $61.7(32)$ & $87.7(35)$ & $2.48(39)$ & $1.68(45)$ & $7.3(41)$ & $29.0(38)$ \\
\hline Arkansas & $.840(47)$ & $.889(48)$ & $.849(50)$ & $55.7(50)$ & $101.8(50)$ & $2.48(41)$ & $1.64(39)$ & $7.7(45)$ & $31.3(50)$ \\
\hline California & $.880(20)$ & $.917(23)$ & $901(19)$ & $64.9(20)$ & $77.0(20)$ & $2.62(28)$ & $1.61(32)$ & $6.5(27)$ & 27.1 (24) \\
\hline Colorado & $.880(19)$ & $.919(20)$ & $.900(20)$ & $64.7(21)$ & $78.2(23)$ & $2.66(26)$ & $1.60(27)$ & $6.4(25)$ & $27.0(22)$ \\
\hline Connecticut & $.888(9)$ & $.920(18)$ & $.909(6)$ & $66.1(10)$ & $78.3(24)$ & $2.47(42)$ & $1.68(47)$ & $7.0(34)$ & $27.7(28)$ \\
\hline Delaware & $.866(31)$ & $.907(32)$ & $.889(29)$ & $62.6(29)$ & $84.6(33)$ & $2.45(43)$ & $1.67(42)$ & $7.3(40)$ & $28.9(34)$ \\
\hline D. C. & $.848(39)$ & $.892(45)$ & $.874(36)$ & $59.5(39)$ & $93.9(40)$ & $2.22(51)$ & $1.76(51)$ & $8.5(51)$ & $31.2(49)$ \\
\hline Florida & $.847(40)$ & $.894(43)$ & $.868(40)$ & $59.1(42)$ & $97.2(47)$ & $2.32(50)$ & $1.75(50)$ & $8.3(50)$ & $30.9(48)$ \\
\hline Georgia & $.845(45)$ & $.894(42)$ & $.860(43)$ & $58.0(44)$ & $93.9(41)$ & $2.54(36)$ & $1.63(36)$ & $7.3(39)$ & $30.0(40)$ \\
\hline Hawaii & $.876(25)$ & $.915(26)$ & $.898(24)$ & $64.1(24)$ & $78.7(25)$ & $2.60(32)$ & $1.60(28)$ & $6.5(28)$ & $27.5(26)$ \\
\hline Idaho & $.891(6)$ & $.927(4)$ & $.906(10)$ & $66.1(11)$ & $72.3(6)$ & $2.96(2)$ & $1.50(3)$ & $5.5(2)$ & $25.4(5)$ \\
\hline Illinois & $.878(22)$ & .917 (24) & $.899(23)$ & $64.7(22)$ & 76.9 (19) & $2.66(27)$ & $1.59(26)$ & $6.4(24)$ & $27.0(21)$ \\
\hline Indiana & $.886(17)$ & $.924(13)$ & $.903(16)$ & $65.7(15)$ & $73.4(9)$ & $2.84(9)$ & $1.53(8)$ & $5.7(8)$ & $25.8(7)$ \\
\hline Kansas & $.871(28)$ & $.912(28)$ & $.890(28)$ & $63.1(28)$ & $83.1(31)$ & $2.61(30)$ & $1.62(35)$ & $6.8(31)$ & $27.9(32)$ \\
\hline Kentucky & $.839(48)$ & $.890(47)$ & $.853(47)$ & $56.9(47)$ & $96.7(45)$ & $2.54(35)$ & $1.64(38)$ & $7.5(42)$ & $30.4(45)$ \\
\hline Louisiana & $.838(49)$ & $.889(49)$ & $.856(46)$ & $57.2(46)$ & $97.6(48)$ & $2.44(45)$ & $1.67(43)$ & $7.8(46)$ & $30.8(46)$ \\
\hline Maine & $.896(3)$ & $.931(3)$ & .909 (3) & $66.7(4)$ & $72.2(5)$ & $2.91(4)$ & $1.52(5)$ & $5.5(4)$ & $25.2(3)$ \\
\hline Maryland & $.878(21)$ & $.917(22)$ & $.899(22)$ & $64.6(23)$ & $76.6(18)$ & $2.70(24)$ & $1.57(18)$ & $6.2(21)$ & $26.9(20)$ \\
\hline Massachusetts & $.846(42)$ & $.896(39)$ & $.865(42)$ & $59.4(40)$ & $88.3(38)$ & $2.60(31)$ & $1.62(33)$ & $7.0(33)$ & $28.9(37)$ \\
\hline Michigan & $.887(12)$ & $.924(9)$ & $.905(12)$ & $66.1(9)$ & $72.7(7)$ & $2.84(10)$ & $1.54(11)$ & $5.8(10)$ & $25.8(9)$ \\
\hline Minnesota & $.874(27)$ & $.915(25)$ & $.892(26)$ & $63.7(26)$ & $79.3(26)$ & $2.71(18)$ & $1.58(21)$ & $6.3(22)$ & 27.1 (23) \\
\hline Mississippi & $.826(51)$ & $.879(51)$ & $.832(51)$ & $53.0(51)$ & $107.4(51)$ & $2.34(49)$ & $1.64(40)$ & $7.9(49)$ & $32.2(51)$ \\
\hline Missouri & $.856(36)$ & $.902(36)$ & $.874(35)$ & $60.5(35)$ & $88.1(36)$ & $2.57(33)$ & $1.64(37)$ & $7.1(37)$ & $28.9(36)$ \\
\hline Montana & $.887(15)$ & $.924(8)$ & $.903(17)$ & $65.5(17)$ & 73.9 (12) & $2.88(6)$ & $1.52(17)$ & $5.7(7)$ & $25.8(8)$ \\
\hline Nebraska & $.870(29)$ & $.912(29)$ & $.887(30)$ & $62.5(30)$ & $83.6(32)$ & $2.61(29)$ & $1.60(29)$ & $6.6(30)$ & $27.8(29)$ \\
\hline
\end{tabular}


TABLE I (Concluded)

\begin{tabular}{|c|c|c|c|c|c|c|c|c|c|}
\hline \multirow{2}{*}{$\begin{array}{l}\text { Measures of } \\
\text { Equality }\end{array}$} & \multicolumn{3}{|c|}{$E$} & \multirow[b]{2}{*}{$\begin{array}{c}\text { Concentration } \\
\text { ratio } \%\end{array}$} & \multirow{2}{*}{$\begin{array}{c}\text { Coefficient } \\
\text { of } \\
\text { variation }\end{array}$} & \multirow[b]{2}{*}{$\begin{array}{l}\text { Pareto } \\
\text { coefficient }\end{array}$} & \multirow[b]{2}{*}{$\begin{array}{l}\text { Gini } \\
\text { coefficient }\end{array}$} & \multicolumn{2}{|c|}{$\begin{array}{l}\text { Per cent of total } \\
\text { income earned by }\end{array}$} \\
\hline & $\begin{array}{c}\bar{W}_{1} \\
\beta=5000\end{array}$ & $\begin{array}{c}\bar{W}_{2} \\
\phi=5000\end{array}$ & $\begin{array}{c}\bar{W}_{3} \\
\theta=5000\end{array}$ & & & & & Top $1 \%$ & Top $10 \%$ \\
\hline Nevada & $.887(11)$ & $.923(16)$ & $.907(8)$ & $66.1(12)$ & $73.9(13)$ & $2.70(20)$ & $1.58(20)$ & $6.1(17)$ & $26.4(15)$ \\
\hline New Hampshire. & $.899(1)$ & $.932(2)$ & $.916(1)$ & $68.0(2)$ & $71.0(3)$ & $2.83(11)$ & $1.55(12)$ & $5.7(9)$ & $25.3(4)$ \\
\hline New Jersey & $.889(7)$ & $.924(12)$ & $.909(4)$ & $66.4(6)$ & $73.6(10)$ & $2.67(25)$ & $1.58(23)$ & $6.2(18)$ & $26.4(17)$ \\
\hline New Mexico & $.860(34)$ & $.906(33)$ & $.879(33)$ & $61.3(33)$ & $83.0(30)$ & $2.70(21)$ & $1.57(17)$ & $6.4(26)$ & $27.9(31)$ \\
\hline New York & $.876(26)$ & $.913(27)$ & $.897(25)$ & $64.1(25)$ & $81.4(27)$ & $2.49(38)$ & $1.66(41)$ & $7.1(35)$ & $28.2(33)$ \\
\hline North Carolina . & $.847(41)$ & $.895(41)$ & $.860(44)$ & $58.0(43)$ & $97.0(46)$ & $2.42(46)$ & $1.68(44)$ & $7.6(44)$ & $30.2(43)$ \\
\hline North Dakota . & $.877(24)$ & $.919(21)$ & $.891(27)$ & $63.2(27)$ & $77.4(27)$ & $2.92(3)$ & $1.48(2)$ & $5.6(5)$ & $26.4(14)$ \\
\hline Ohio & $.887(10)$ & $.924(11)$ & $.905(11)$ & $66.1(8)$ & $73.7(11)$ & $2.80(13)$ & $1.56(15)$ & $6.0(12)$ & $26.0(12)$ \\
\hline Oklahoma & $.850(38)$ & $.897(38)$ & $.868(39)$ & $59.2(41)$ & $93.6(39)$ & $2.45(44)$ & $1.68(46)$ & $7.6(43)$ & $30.0(40)$ \\
\hline Oregon & $.887(14)$ & $.923(15)$ & $.905(13)$ & $65.9(13)$ & $75.6(16)$ & $2.71(19)$ & $1.59(24)$ & $6.2(19)$ & $26.4(15)$ \\
\hline Pennsylvania & $.885(18)$ & $.922(17)$ & $.903(15)$ & $65.6(16)$ & $76.4(17)$ & $2.69(22)$ & $1.58(22)$ & $6.2(20)$ & $26.6(19)$ \\
\hline Rhode Island . & $.891(5)$ & $.926(6)$ & $.907(7)$ & $66.5(5)$ & $74.6(14)$ & $2.76(15)$ & $1.57(19)$ & $6.0(15)$ & $26.0(11)$ \\
\hline South Carolina . & $.846(43)$ & $.895(40)$ & $.856(45)$ & $57.4(45)$ & $94.2(42)$ & $2.55(34)$ & $1.61(31)$ & $7.1(36)$ & $29.6(39)$ \\
\hline South Dakota . & $.866(32)$ & $.910(31)$ & $.878(34)$ & $60.1(34)$ & $82.9(28)$ & $2.84(8)$ & $1.52(4)$ & $6.0(14)$ & $27.4(25)$ \\
\hline Tennessee & $.838(50)$ & $.889(50)$ & $.852(49)$ & $56.7(49)$ & $99.7(49)$ & $2.38(48)$ & $1.69(48)$ & $7.9(48)$ & $30.9(47)$ \\
\hline Texas & $.845(44)$ & $.893(44)$ & $.865(41)$ & $58.8(37)$ & $94.7(43)$ & $2.39(47)$ & $1.70(49)$ & $7.8(47)$ & $30.4(44)$ \\
\hline Utah & $.899(2)$ & $.932(1)$ & $.915(2)$ & $68.0(1)$ & $69.2(2)$ & $2.89(5)$ & $1.52(6)$ & $5.5(2)$ & $24.9(2)$ \\
\hline Vermont & $.887(13)$ & $.924(10)$ & $.902(18)$ & $65.3(18)$ & $77.2(21)$ & $2.74(17)$ & $1.56(14)$ & $6.0(16)$ & $26.4(18)$ \\
\hline Virginia & $.850(37)$ & $.899(37)$ & $.868(38)$ & $59.5(38)$ & $88.2(37)$ & $2.53(37)$ & $1.60(30)$ & $6.9(32)$ & $28.9(34)$ \\
\hline Washington & $.892(4)$ & $.927(5)$ & $.910(3)$ & $66.9(3)$ & $71.2(4)$ & $2.88(7)$ & $1.53(9)$ & $5.7(6)$ & $25.5(6)$ \\
\hline West Virginia & $.858(35)$ & $.905(34)$ & $.871(37)$ & $60.1(36)$ & $85.2(34)$ & $2.76(14)$ & $1.55(13)$ & $6.3(23)$ & $27.9(30)$ \\
\hline Wisconsin & $.886(16)$ & $.923(14)$ & $.904(14)$ & $65.9(14)$ & $74.6(15)$ & $2.75(16)$ & $1.56(16)$ & $6.0(13)$ & $26.1(13)$ \\
\hline Wyoming & $.889(8)$ & $.926(7)$ & $.907(9)$ & $66.2(7)$ & $73.1(8)$ & $2.80(12)$ & $1.54(10)$ & $5.8(10)$ & $25.8(9)$ \\
\hline
\end{tabular}


TABLE II

Matrix of Correlation Coefficient Between $E\left(\bar{W}_{1}\right), E\left(\overline{W_{2}}\right)$, and $E\left(\bar{W}_{3}\right)$, with Various $\beta, \phi$, and $\theta$

\begin{tabular}{|c|c|c|c|c|c|c|c|c|c|c|c|c|c|c|c|c|c|}
\hline & & \multicolumn{8}{|c|}{$\begin{array}{c}E_{1}=E\left(\bar{W}_{1}\right) \\
\beta \text { in thousands }\end{array}$} & \multicolumn{4}{|c|}{$\begin{array}{c}E_{2}=E\left(\bar{W}_{2}\right) \\
\phi \text { in thousands }\end{array}$} & \multicolumn{4}{|c|}{$\begin{array}{c}E_{3}=E\left(\vec{W}_{3}\right) \\
\theta \text { in thousands }\end{array}$} \\
\hline & & 0.5 & 0.8 & 1.0 & 5.0 & 8.0 & 10 & 50 & 100 & 1.0 & 3.0 & 5.0 & 7.0 & 1.0 & 3.0 & 5.0 & 7.0 \\
\hline & 0.5 & 1.00 & .87 & .99 & .85 & .68 & .60 & .25 & .21 & .94 & .86 & .83 & .77 & .98 & .96 & .92 & .89 \\
\hline & 0.8 & & 1.00 & .88 & .79 & .64 & .56 & .25 & .22 & .85 & .79 & .76 & .71 & .88 & .86 & .84 & .81 \\
\hline$E_{1}=E\left(\vec{W}_{1}\right)$ & 1.0 & & & 1.00 & .87 & .69 & .60 & .25 & .21 & .95 & .88 & .84 & .78 & .99 & .97 & .94 & .90 \\
\hline$\beta$ in & 5.0 & & & & 1.00 & \begin{tabular}{|c|}
.95 \\
\end{tabular} &.$\overline{91}$ & .68 & .65 & .98 & .96 & .99 & .99 & .92 & .96 & .99 & .99 \\
\hline thousands & 8.0 & & & & & 1.00 & .99 & .87 & .85 & .88 & .89 & .97 & .99 & .78 & .85 & .90 & .94 \\
\hline & 10 & & & & & & 1.00 & .92 & .91 & .82 & .84 & .94 & .97 & .70 & .78 & .84 & .89 \\
\hline & 50 & & & & & & & 1.00 & .99 & .53 & .59 & .73 & .79 & .37 & .47 & .57 & .64 \\
\hline & 100 & & & & & & & & 1.00 & .50 & .56 & .71 & .77 & .33 & .44 & .53 & .61 \\
\hline & & & & & & \multirow{4}{*}{\multicolumn{3}{|c|}{$\begin{array}{c}E_{2}=E\left(\bar{W}_{2}\right) \\
\phi \text { in } \\
\text { thousands }\end{array}$}} & 1.0 & 1.00 & .96 & .97 & .94 & .98 & .99 & .99 & .99 \\
\hline & & & & & & & & & 3.0 & & 1.00 & .95 & .93 & .92 & .95 & .96 & .96 \\
\hline & & & & & & & & & 5.0 & & & 1.00 & .99 & .90 & .95 & .98 & .99 \\
\hline & & & & & & & & & 7.0 & & & & 1.00 & .86 & .91 & .95 & .98 \\
\hline & & & & & & & & & & \multirow{4}{*}{\multicolumn{3}{|c|}{$\begin{array}{c}E_{3}=E\left(\bar{W}_{3}\right) \\
\theta \text { in } \\
\text { thousands }\end{array}$}} & 1.0 & 1.00 & .99 & .97 & .95 \\
\hline & & & & & & & & & & & & & 3.0 & & 1.00 & .99 & .98 \\
\hline & & & & & & & & & & & & & 5.0 & & & 1.00 & .99 \\
\hline & & & & & & & & & & & & & 7.0 & & & & 1.00 \\
\hline
\end{tabular}

TABLE III

Correlation Coefficients Between the Various Traditional Measures and $E\left(\bar{W}_{1}\right)$ with Various Parameters

\begin{tabular}{|c|c|c|c|c|c|c|c|}
\hline $\begin{array}{c}E\left(\bar{W}_{1}\right) \\
\beta \text { in } \\
\text { thousands }\end{array}$ & $G$ & $V$ & $\alpha$ & $\delta$ & $P_{1}$ & $P_{0}$ & $P_{10}$ \\
\hline 0.5 & .86 & -.81 & .45 & -.31 & -.54 & -.64 & -.75 \\
\hline 0.8 & .92 & -.87 & .46 & -.31 & -.57 & -.68 & -.79 \\
\hline 5.0 & .99 & -.97 & .75 & -.65 & -.85 & -.91 & -.95 \\
\hline 8.0 & .97 & -.93 & .85 & -.78 & -.91 & -.95 & -.96 \\
\hline 10 & .86 & -.89 & .87 & -.81 & -.92 & -.94 & -.94 \\
\hline 20 & .71 & -.76 & .89 & -.87 & -.91 & -.88 & -.85 \\
\hline 50 & .60 & -.68 & .88 & -.88 & -.87 & -.83 & -.79 \\
\hline 100 & .57 & -.65 & .88 & -.89 & -.86 & -.82 & -.77 \\
\hline
\end{tabular}


To formalize these findings, numerous comparisons were made between $E\left(\bar{W}_{1}\right), E\left(\bar{W}_{2}\right)$ and $E\left(\bar{W}_{3}\right)$ with varying parameters $\beta, \phi$, and $\theta$; the results are shown as the correlation matrix of Table II. Also computed was a more detailed comparison of $E\left(\bar{W}_{1}\right)$ with the traditional measures of equality. These results are shown in Table III.

Regarding the usefulness of the welfare-oriented index as a measure of equality of income for policy purposes, the results in Table II demonstrate that the shape of $\bar{W}(x)$ is crucial to the order of equality derived from the index. For example, when $\bar{W}_{1}$ is used, $E_{1}(\beta=1,000)$ has a correlation of only 0.25 with $E_{1}(\beta=50,000)$. If society could not specify an appropriate welfare function well within this range, judgments about the relative equality of various income distributions would be meaningless.

On the other hand, as the blocked-out portions of Table II indicate, substantially high correlations appear between the various index forms with $\beta$ ranging from 1,000 to 10,000 and $\phi$ and $\theta$ ranging from 1,000 to 7,000 . This suggests that reasonable policy judgments could be made about the relative equality of various income distributions if society could but spell out a welfare function $\vec{W}$ constrained within a range of parameters. Since the results are invariant to at least this extent under variations in $\bar{W}$, an additional implication is that the limiting assumption about interaction phenomena may not be a serious shortcoming of the empirical model.

Turning to the proposition that the traditional measures of income equality embody implicit welfare judgments, note the results of Table III and the corresponding Figure 2: The concentration ratio $(G)$ is highly correlated with $E\left(\bar{W}_{1}\right)$ when $\beta$ ranges from 500 to 8,000 , and it would thus seem to be the preferred measure of equality if the appropriate welfare function were contained in this set of functions. As $\beta$ increases, however, correlations between $E$ and $G$ fall and other measures become preferable. When $\beta$ takes on a value around 10,000 , then $P_{5}$ and $P_{10}$ seem to be more appropriate measures of equality; similarly, with $\beta$ around $20,000, P_{1}$ is the best measure. And, interestingly, if $\beta$ is allowed to increase to values of 50,000 and 100,000, the Pareto $\alpha$ and Gini $\delta$ become the most appropriate of the traditional measures, in terms of their correspondence with the equality index.

The results of such comparisons bcar on the implicit assumptions made as to the nature of the welfare function when the "traditional" measures of income equality are utilized. More precisely, when one uses the concentration ratio to measure equality, he assumes $\bar{W}_{1}(\beta=5,000)$ to be a more reasonable welfare function than $\bar{W}_{1}(\beta=50,000)$; otherwise, he should use an alternative measure, perhaps Pareto's $\alpha$, as his measure of equality in its welfare connotation.

Another result of note concerns the apparent reasonableness of $P_{1}, P_{5}$, and $P_{10}$ as measures of equality. They appear more adequate indicators of income equality than $G$ or $V$ when $\beta$ is large. Such simple measures are useful when a paucity of data prevents use of more complex indexes. And, apparently these measures generate reasonably good judgments as to equality of the income distribution despite their simplicity. 


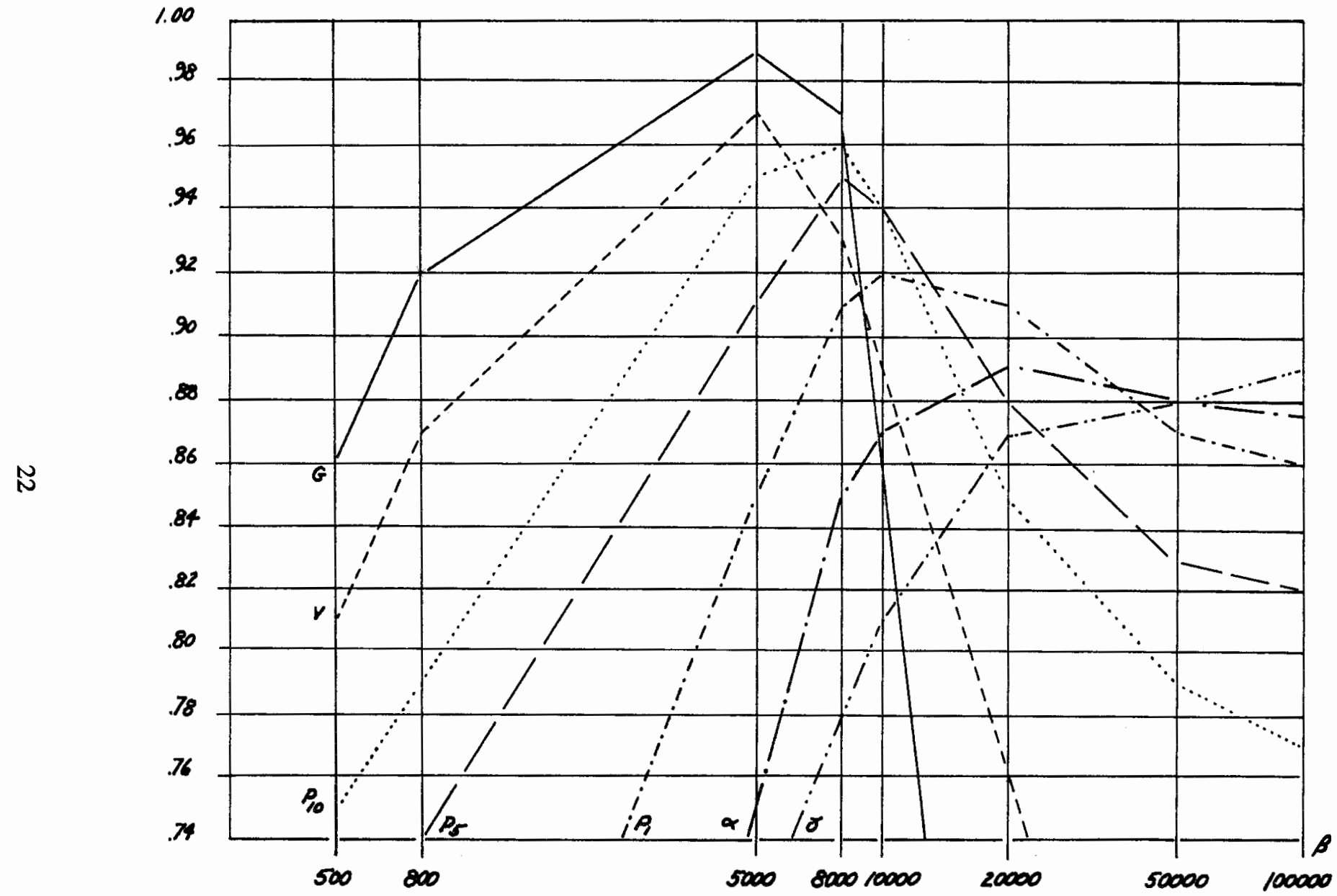

FIGURE 2. Correlation between the various measures of equality $\left(G, V, \alpha, \delta, P_{10}, P_{5}\right.$, and $\left.P_{1}\right)$ and $E$ using $\bar{W}_{1}$ with parameters $\beta$ ranging from 500 to 100,000 . 


\section{Conclusions and Caveats}

It must be reiterated that the findings reached above depend upon the notion that income equality is appropriately measured in terms of the relative amount of welfare generated by income distributions. Granting this, then judgments about the equality of alternative distributions of income require more explicit designation of the welfare function than is commonly accorded such judgments.

While any welfare function must decline at the margin to make the preferability of a more equal distribution meaningful at all, the possible shapes for a welfare function which fits this constraint are manifold. We have used three such general functions, but many others might be incorporated along the lines indicated.

Lastly, it must be noted that if the welfare function were specified for policy purposes, the appropriate function to be maximized is not equality in terms of the index $E$, but rather that of aggregate welfare for society. For this reason, one could not conclude that any policy which generates more equality in terms of the index is necessarily a "good" policy. For example, adopting a progressive income tax might generate more equality, but if it impairs incentives to labor at the margin and hence reduces aggregate income and utility, it may be a "bad" policy in total welfare terms.

\section{APPENDIX}

\section{Class Means and the Percentage Distribution of Income}

Both the Pareto and Gini coefficients were obtained by fitting least squares lines to relevant observations for the median class and above in each distribution.

The Pareto coefficient $\alpha$ was also incorporated into an estimation procedure for class means for the upper end of the distribution, rather than using midpoints of the intervals. An alternative procedure is used for classes below the median class. While it is true that for perfectly symmetric distributions, the use of mid-points will yield an unbiased estimate of the overall mean of the distribution, this is not the case for an estimate of the variance of a symmetric distribution. Estimates of variance will have an upward bias using mid-points. Moreover, the distributions of income of the present study are markedly skewed, adding still another possibility for bias, for both the mean and the variance.

The estimation procedure for obtaining class means for the upper end of the income distributions is as follows:

Given the Pareto relationship

$$
\log N=K+\alpha \log x
$$

where $N=$ the number of income units earning at least $x$, then we write the cumulative frequency function for $x$ as

$$
f(x \geq r)=\int_{\tau}^{\infty} f(x=r) d x=k x^{\alpha}, \alpha<0,
$$


from the Pareto relationship. Therefore,

$$
f(x)=\frac{d}{d x} 1-k x^{\alpha}=-\alpha k x^{\alpha-1} .
$$

Total frequency in any interval, say $\left(x, x^{\prime}\right)$, is

$$
\int_{x}^{x^{\prime}} f(r) d r=\int_{x}^{x^{\prime}}-\alpha k r^{\alpha-1} d r=k\left[x^{\alpha}-x^{\prime \alpha}\right] .
$$

Similarly, total income within $\left(x, x^{\prime}\right)$ is given by:

$$
\int_{x}^{x^{\prime}}-r \alpha k r^{\alpha-1} d r=\int_{x}^{x^{\prime}}-\alpha k r^{\alpha} d r=k\left[\frac{\alpha}{\alpha+1}\right]\left[x^{\alpha+1}-x^{\prime \alpha+1}\right], \alpha<-1 .
$$

Finally, the estimated mean for the interval $\left(x, x^{\prime}\right)$ based on the Pareto line is

$$
\hat{\mu}_{\left(x, x^{\prime}\right)}=\left[\frac{\alpha}{\alpha+1}\right]\left[\frac{x^{\alpha+1}-x^{\alpha+1}}{x^{\alpha}-x^{\prime \alpha}}\right] .
$$

For the open-end interval, say $(x, \infty)$,

$$
\hat{\mu}_{(x, \infty)}=\lim _{x^{\prime} \rightarrow \infty} \hat{\mu}_{\left(x, x^{\prime}\right)}=\left[\frac{\alpha}{\alpha+1}\right] x \quad \text { for } \alpha<-1 .
$$

These estimators are used to estimate class means for the median class and classes above the median. For the remaining intervals another procedure is used, that of obtaining a linear approximation to the frequency function over each interval (Cf. [1]).

Historiquement, l'usage par les économistes du terme "égalitê" en ce qui concerne une distribution des revenus a porté davantage sur certaines caractéristiques statistiques de la distribution que sur un concept consistant. Un tel concept repose bien entendu sur des hypothèses de bien-être appropriées relatives au revenu et à sa distribution, hypothèses dont le contenu est resté pour la plus grande partie implicite (et inconnu) dans les discussions sur l'égalité du revenu.

Notre but dans cet article est double. Nous désirons d'abord dégager une mesure précise de l'égalité se rapportant au revenu. Nous y arrivons par l'intermédiaire d'hypothèses adéquates sur la fonction de bien-être social. Cela fournit un "index" d'égalité décrivant ce qu'une distribution donnée implique par rapport au bien-être maximum qui peut être dérivé du revenu total que cette distribution représente. La mesure est donc fonction des attributs de bien-être du revenu, au sujet desquels nous ne connaissons guère en réalité.

Cette impasse nous conduit à examiner la sensibilité de l'indice vis-à-vis des caractéristiques de la fonction de bien-être, ce qui est fait en comparant les rangs (quality ranks) pour les états des Etats-Unis en 1960 à l'aide de diverses formes traditionnelles et entre des courbes d'une même forme. Conclusion secondaire intéressante, le résultat des mesures courantes de qualité est testé par rapport à l'index de bien-être afin de dégager les implications relatives à leur contenu de bien-être.

On découvre que l'indice d'égalité est, pour certains degrés (ranges) de la fonction de bien-être, insensible à sa caractéristique. Les résultats conduisent 
directement à des conclusions concernant les mesures courantes d'égalité, leur utilité pour la comptabilité correcte des différences d'égalité parmi des distributions de revenus alternatives et, de façon concomitante, leurs inputs implicites de bien-être.

\section{REFERENCES}

1. Aigner, D. J. "On a Calculation Technique for the Moments of Frequency Distributions in Grouped Form", Proceedings of the ASA, August 1966, p. 332.

2. Boulding, Kenneth. Principles of Economic Policy, Englewood Cliffs, 1958.

3. Bowman, Mary Jean. "A Graphical Analysis of Personal Income Distribution in the United States", Am. Econ. Rev., September 1945, 35, 607-28.

4. Dalton, Hugh. "Measurement of the Inequality of Incomes", Econ. Jour., September 1920, 30, 348-61.

5. GinI, CoRrado. "Measurement of Inequality of Incomes", Econ. Jour., March $1921,31,124-26$.

6. KRAVIS, IrVING B. "International Differences in the Distribution of Income", Rev. Econ. Stat., December 1960, 42, 408-16.

7. KuzNets, Simon. "Economic Growth and Income Inequality", Am. Econ. Rev., March 1955, 45, 1-28.

8. LeRner, ABba. The Economics of Control, New York, 1944.

9. LitTLE, I. M. D. A Critique of Welfare Economics, Oxford, 1947.

10. Mandelbrot, Benort. "Stable Paretian Random Functions and the Multiplicative Variation of Income", Econometrica, October 1961, 29, 517-43.

11. Schutz, Robert R. "On the Measurement of Income Inequality", Am. Econ. Rev., March, 1951, 41, 107-22.

12. YNTEMA, DwiGht B. "Measures of the Inequality in the Personal Distribution of Wealth or Income", Jour. Am. Stat. Ass., December 1933, 28, 423-33. 